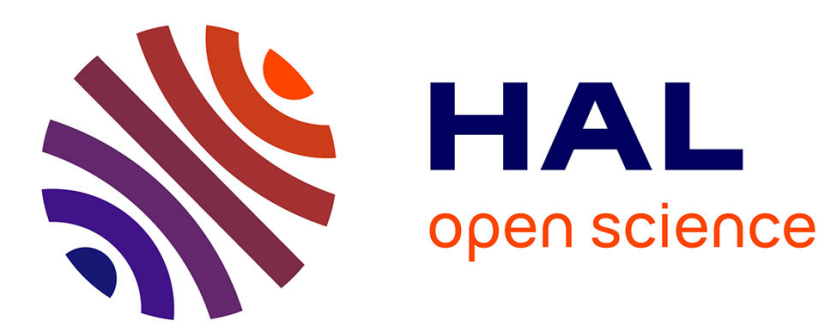

\title{
Variation in biomass expansion factors for China's forests in relation to forest type, climate, and stand development
}

Yunjian Luo, Xiaoke Wang, Xiaoquan Zhang, Yin Ren, Hendrik Poorter

\section{- To cite this version:}

Yunjian Luo, Xiaoke Wang, Xiaoquan Zhang, Yin Ren, Hendrik Poorter. Variation in biomass expansion factors for China's forests in relation to forest type, climate, and stand development. Annals of Forest Science, 2013, 70 (6), pp.589-599. 10.1007/s13595-013-0296-6 . hal-01201500

\author{
HAL Id: hal-01201500 \\ https://hal.science/hal-01201500
}

Submitted on 17 Sep 2015

HAL is a multi-disciplinary open access archive for the deposit and dissemination of scientific research documents, whether they are published or not. The documents may come from teaching and research institutions in France or abroad, or from public or private research centers.
L'archive ouverte pluridisciplinaire HAL, est destinée au dépôt et à la diffusion de documents scientifiques de niveau recherche, publiés ou non, émanant des établissements d'enseignement et de recherche français ou étrangers, des laboratoires publics ou privés. 


\title{
Variation in biomass expansion factors for China's forests in relation to forest type, climate, and stand development
}

\author{
Yunjian Luo • Xiaoke Wang • Xiaoquan Zhang • \\ Yin Ren • Hendrik Poorter
}

Received: 18 December 2012 / Accepted: 9 May 2013 /Published online: 5 June 2013

(C) INRA and Springer-Verlag France 2013

\begin{abstract}
- Context Biomass expansion factors (BEFs, defined as the ratios of tree component biomass (branch, leaf, aboveground section, root, and whole) to stem biomass) are important parameters for quantifying forest biomass and carbon stock. However, little information is available about possible causes of the variability in BEFs at large scales.

- Aims We examined whether and how BEFs vary with forest types, climate (mean annual temperature, MAT; mean
\end{abstract}

Handling Editor: Shuqing Zhao

Y Luo and X Wang contributed equally to this work.

Contribution of the co-authors Y Luo, X Wang, and X Zhang conceived and designed the work; Y Luo and X Wang analyzed the data; Y Luo, X Wang, X Zhang, Y Ren, and H Poorter wrote the paper; $\mathrm{X}$ Wang and $\mathrm{X}$ Zhang supervised the work.

\section{Y. Luo $(\bowtie) \cdot$ Y. Ren}

Key Laboratory of Urban Environment and Health,

Xiamen Key Laboratory of Urban Metabolism,

Institute of Urban Environment, Chinese Academy of Sciences,

1799 Jimei Avenue, Xiamen 361021, China

e-mail: yjluo@iue.ac.cn

Y. Ren

e-mail: yren@iue.ac.cn

X. Wang $(\bowtie)$

State Key Laboratory of Urban and Regional Ecology,

Research Center for Eco-Environmental Sciences,

Chinese Academy of Sciences, 18 Shuangqing Road,

Haidian District, Beijing 100085, China

e-mail: wangxk@rcees.ac.cn

\section{Zhang}

The Nature Conservancy China Program,

9 Jianguomenwai Avenue, Chaoyang District, Beijing 100600, China

e-mail: zxiaoquan@tnc.org

H. Poorter

IBG-2 Plant Sciences, Forschungszentrum Jülich,

52425 Jülich GmbH, Germany

e-mail: h.poorter@gmail.com annual precipitation, MAP), and stand development (stand age and size) at the national scale for China.

- Method Using our compiled biomass dataset, we calculated values for BEFs and explored their relationships to forest types, climate, and stand development.

- Results BEFs varied greatly across forest types and functional groups. They were significantly related to climate and stand development (especially tree height). However, the relationships between BEFs and MAT and MAP were generally different in deciduous forests and evergreen forests, and BEF-climate relationships were weaker in deciduous forests than in evergreen forests and pine forests.

- Conclusion To reduce uncertainties induced by BEFs in estimates of forest biomass and carbon stock, values for BEFs should be applied for a specified forest, and BEF functions with influencing factors (e.g., tree height and climate) should be developed as predictor variables for the specified forest.

Keywords Biomass expansion factors - Forest type . Temperature $\cdot$ Precipitation $\cdot$ Stand development $\cdot$ China

\section{Introduction}

Forests play a crucial role in regional and global terrestrial carbon cycles because they sequester and store more carbon than other terrestrial ecosystems and could mitigate anthropogenic greenhouse gas effects (Houghton et al. 2009; Shao et al. 2011). However, regional and global forest biomass and carbon estimates are still controversial because, even if the forest inventory data are nearly identical, different transformation factors or equations may be used (Fang et al. 2006). This suggests that there is a strong need to select, develop, and apply appropriate factors or equations for accurate estimation of forest biomass or carbon (Somogyi et al. 2007). Traditionally, large-scale biomass carbon estimates are obtained using forest inventory data with the aid of various transformation factors, such as wood density (WD), biomass expansion factors 
(BEFs), and carbon fraction (CF) (Intergovernmental Panel on Climate Change (IPCC) 2003; Somogyi et al. 2007; Usoltsev and Hoffman 1997). Forest inventory-based estimates are usually used to calibrate remotely sensed estimates (Ren et al. 2012). However, these estimates are very sensitive to transformation factors because of their large variation (IPCC 2003). Thus, an important current topic in forest carbon accounting and management is how to reduce uncertainties associated with the use of transformation factors.

One method to estimate forest biomass carbon is to convert the widely available volume data using WD to biomass, then by multiplication with BEFs to estimate the tree component (e.g., branch, leaf, and root), aboveground section, or whole tree biomass, and then by CF to convert to biomass carbon (IPCC 2003; Somogyi et al. 2007; Usoltsev and Hoffmann 1997). This method has been used to quantify regional and global forest biomass and carbon stocks (e.g., Brown et al. 1989; Johnson and Sharpe 1983; Kauppi et al. 1995; Nogueira et al. 2008). CF is relatively constant, and the values 0.45 and 0.50 are frequently used (Zheng et al. 2007). WD data are easily obtained by laboratory measurements, but BEFs are not usually determined by traditional forestry practices (Levy et al. 2004). It is recommended that specific BEFs should be applied to different tree species, forest types, and regions, because of their large variation (IPCC 2003).

Recent studies suggest that transformation factors (e.g., $\mathrm{WD}, \mathrm{BEFs}$, and CF) are not constant, but vary with forest type, stand development, climate, and other growing conditions (IPCC 2003; Zheng et al. 2007). The age- and sizeinduced variation in BEFs for one forest type has been highlighted (e.g., Brown et al. 1989; Fukuda et al. 2003; Lim et al. 2012; Tobin and Nieuwenhuis 2007). Because trees demonstrate different biomass allocation patterns and adaptive strategies in response to abiotic factors such as temperature, water, and nutrients (Poorter et al. 2012), BEFs are hypothesized to vary with forest types and abiotic factors, but this variation has not been well examined to date. Furthermore, little information is available about variability in BEFs across biological and environmental gradients at large scales. This has important implications for how resources should be invested to accurately determine BEFs, thereby reducing uncertainties in estimates of forest biomass and carbon stock at large scales. For example, if there are significant relationships between BEFs and climate, climatic data could be used in the prediction of BEFs; if there are none, it would be better to invest more resources for developing BEF functions with stand age and/or size as predictor variables without integrating climatic data.

China has a diverse range of forest types, ranging from tropical rainforest to boreal forest (Zhang 2007). It has a good representation of global biome heterogeneity and climatic gradients and thus provides an excellent opportunity to explore possible sources of variation in BEFs on a national scale. IPCC guidelines provide default values for aboveground $\mathrm{BEF}$ (the ratio of aboveground biomass to the biomass of merchantable volume), which were obtained using biomass data from regions and nations other than China (IPCC 2003). A large uncertainty could well be introduced by use of these default values for forest biomass and carbon estimation in China. During recent years, we have compiled a large forest biomass dataset for China based on a literature survey. Using our compiled dataset, we determined forest type-specific values of various BEFs and then examined whether and how BEFs varied with forest types, climate, and stand age and size (e.g., diameter, tree height, and standing volume) at the national scale. Any relationships between BEFs and climate were examined in contrasting forests (deciduous vs. evergreen), because deciduous and evergreen trees are widely considered to have different ecological strategies in response to their environments (Kloeke et al. 2012) and also in pine (Pinus spp.) forests, due to their widespread occurrence and increasing worldwide use in afforestation and reforestation efforts (Zhang 2007).

\section{Materials and methods}

\subsection{The dataset}

A large forest biomass dataset for China (excluding Taiwan Province) was compiled from published biomass studies and from preexisting datasets (Feng et al. 1999; Luo 1996; Wang et al. 2008). These studies, published between 1978 and 2008, were obtained from libraries (i.e., National Library of China and Forestry Library of China) and online databases (i.e., China Knowledge Resource Integrated Database, China Science and Technology Journal Database, and Wanfang Data).

Using the following criteria, all studies and data were critically assessed in order to obtain accurate and representative field biomass measurements. (1) Forests which were strongly influenced by recent disturbances and/or grown in specific sites were excluded: recently disturbed stands (e.g., by pruning, thinning, coppicing, fire, and insect pest), economic forests (stands for producing fruits, edible oils, medicinal herbs, industrial raw materials, etc.), agroforestry systems (stands integrated with crops and/or animals), forested wetlands (e.g., mangroves and swamps), and other stands grown in atypical sites (e.g., urban, desert, riverine, timberline, and heavily eroded sites). (2) The sampling and measuring protocols (or procedures) for the oven-dried mass of tree components (stems, branches, leaves, roots, etc.) should be explicitly described in the original sources, including a suitable survey time (during growing season, especially for deciduous trees), sample plot setting, and biomass sampling of trees (cf. Feng et al. 1999). The biomass of sample trees was measured using destructive harvesting and weighing and then scaled up to stand level (the oven-dried mass per unit area) using the (stratified) average tree method or allometric equation 
method. For a given study area, the allometric equations with one or more stand variables (e.g., diameter at breast height (DBH), tree height, or their combinations) as predictors were developed based on biomass measurements of sample trees and were then used to estimate stand-level biomass within the study area. If biomass data for roots were available in original sources, they should be measured by full excavation to cover enough area (equal to or larger than the average nutrient area the sample trees covered) and to reach the maximum root depth, or be supplemented by soil pit method for fine roots.

Each record consisted of biomass measurements and their supporting information, including the biomass (oven-dried mass per unit area, in megagram per hectare) of each tree component (stems, branches, leaves, roots, etc.) if available, site description (latitude, in degree; longitude, in degree; mean annual temperature (MAT), in degree Celsius; mean annual precipitation (MAP), in millimeter), and stand description (dominant species; forest type; stand origin; stand age, in year; mean DBH, in centimeter; mean tree height, in meter; stand density, in trees per hectare; standing volume, in cubic meter per hectare). Missing geographical coordinates were determined using the geographical center of the sampling site from Google maps (http://maps.google.com). Missing MAT and/or MAP data were estimated by the geographical coordinates from a $30-\operatorname{arc} \sec ($ ca. $1 \mathrm{~km}$ at the equator) resolution global climate database (http:// www.worldclim.org; Hijmans et al. 2005).

In order to calculate values of various BEFs, only records that had biomass data for at least three tree components (i.e., stem, branch, and leaf) were selected from our dataset. A total of 332 sampling sites used in this study showed a sound spatial distribution across China (Fig. 1), ranging from -5.0 to $24.0^{\circ} \mathrm{C}$ in MAT and from 220 to $2,500 \mathrm{~mm}$ in MAP. According to similar dominant species and ecological zones given by China's Vegetation Classification System (Zhang 2007), forest types that maintained an adequate sample size $(n>10)$ were categorized for subsequent analyses (Table 1). In addition, forests were also categorized by leaf lifespan into deciduous forests and evergreen forests, by leaf form into coniferous forests and broadleaved forests, and by stand origin into natural forests and planted forests (plantations).

\subsection{Statistical analysis}

In this study, BEFs were defined as stand-level factors for calculating stand-level biomass. Five separate factors were defined to expand stem biomass estimation to branch, leaf, root, aboveground, and whole tree biomass, respectively:

$\mathrm{BEF}_{i}=W_{i} / W_{\mathrm{s}}$

where $W_{i}$ is the biomass (in megagram per hectare) of the $i$ th tree component (i.e., branch, leaf, and root), aboveground and whole tree, and $W_{s}$ is stem biomass (in megagram per hectare). It should be noted that the biomass of dead branches and understory vegetation was not included in the calculations of BEFs in this study.

Stands less than 20 years old were only used in analysis for effects of stand age and size but not for other effects to minimize the influences of stand age and of unidentifiable factors, such as previous management practices and local soil conditions at early growth stages. Differences in BEFs among forest types were examined using $t$ test for two groups or using oneway analysis of variance followed by multiple comparison tests when more than two groups were compared. When variances were heterogeneous (Levene's test), Games-Howell tests were used; otherwise, Tukey's tests were used. Pearson correlation and regression analyses (linear and nonlinear) were used for quantifying the relationships of BEFs with climate (i.e., MAT and MAP) and stand development (i.e., stand age and size). The relationships between BEFs and climate were further examined in contrasting forests (deciduous vs. evergreen) and in pine forests.

BEFs were $\log$-transformed $\left(\log _{10}\right)$ to reduce the influence of outlying data points. Statistical significance was determined at $P<0.05$. All statistical analyses were conducted in SPSS version 16.0 (SPSS Inc., Chicago, IL), and graphs were drawn in OriginPro version 8.6 (OriginLab Corp., Northampton, MA).

\section{Results}

\subsection{Influences of forest traits on BEFs}

BEFs exhibited great variation in China's forests (Table 1). Means \pm SD of branch, leaf, aboveground, root, and whole BEFs were $0.27 \pm 0.16(n=1,531), 0.18 \pm 0.20 \quad(n=1,531)$, $1.45 \pm 0.32(n=1,531), 0.35 \pm 0.17 \quad(n=1,084)$, and $1.80 \pm$ $0.43(n=1,084)$, respectively. BEFs also varied greatly with forest types (Table 1). Means of BEFs ranged from 0.14 (Eucalyptus forest) to 0.36 (Pinus tabulaeformis forest) for branch BEFs, from 0.06 (deciduous Quercus forest) to 0.28 (Cunninghamia lanceolata forest) for leaf BEFs, from 1.22 (Eucalyptus forest) to 1.64 (P. tabulaeformis forest) for aboveground BEFs, from 0.22 (Casuarina forest) to 0.41 (Robinia pseudoacacia forest) for root BEFs, and from 1.50 (Eucalyptus forest) to 1.98 (C. lanceolata and broadleaved mixed forest) for whole BEFs.

There were large variations in BEFs between functional groups, although not all BEFs differed significantly between functional groups (Table 2). Deciduous forests generally had larger root BEFs than evergreen forests $(P=0.004)$, but smaller leaf BEFs $(P<0.001)$ and aboveground BEFs $(P<$ 


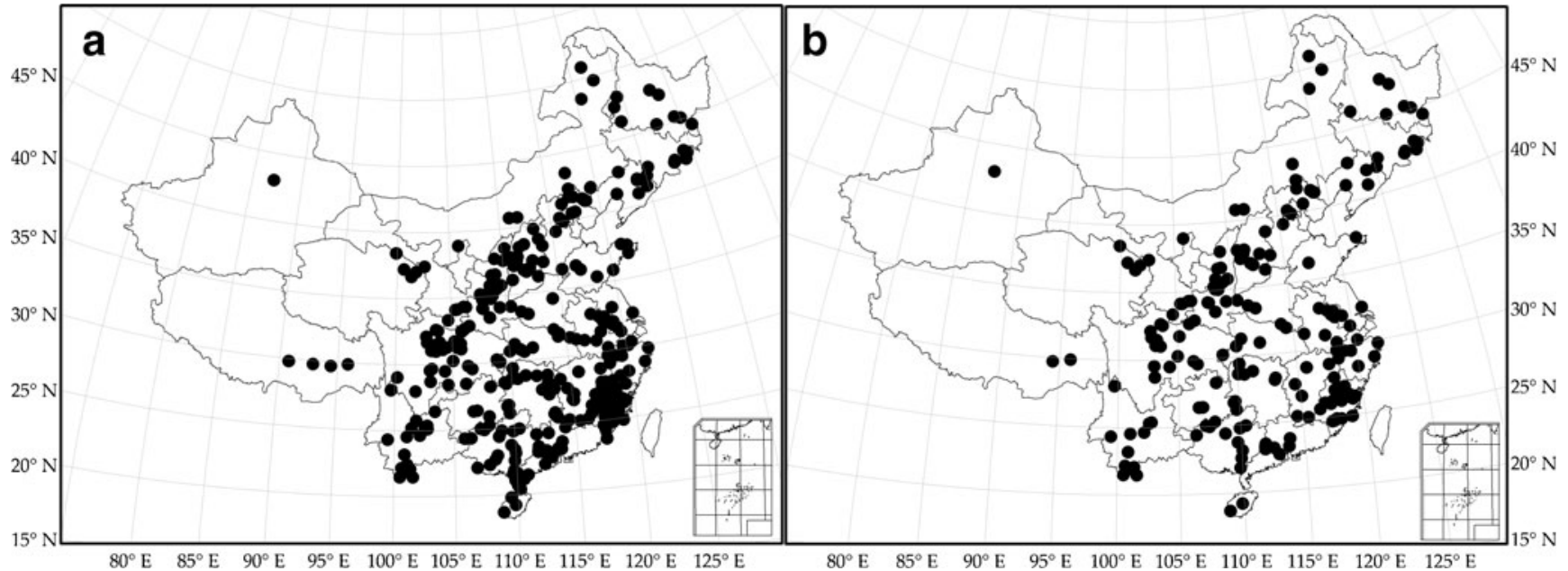

Fig. 1 Spatial distribution of sampling sites used in this study. The distributions of sites (black dots) are presented for a total data and $\mathbf{b}$ older stands ( $\geq 20$ years). Province boundaries are also shown

0.001). Coniferous forests had larger leaf BEFs than broadleaved forests $(P<0.001)$, while branch BEFs $(P<$ $0.001)$ and root BEFs $(P<0.001)$ were smaller. Natural forests generally had larger root BEFs $(P<0.001)$ and whole
BEFs $(P=0.034)$ than plantations, and also smaller leaf BEFs $(P<0.001)$. When major genera were analyzed separately, Picea and Pinus forests had relatively higher BEFs than Cunninghamia, Larix, and deciduous Quercus forests.

Table 1 Statistics of BEFs for main forest types in China (mean \pm SD and the number of samples are in parentheses)

\begin{tabular}{|c|c|c|c|c|c|}
\hline Forest type & Branch BEF & Leaf BEF & $\begin{array}{l}\text { Aboveground } \\
\text { BEF }\end{array}$ & Root BEF & Whole BEF \\
\hline All data & $0.27 \pm 0.16(1,531)$ & $0.18 \pm 0.20(1,531)$ & $1.45 \pm 0.32(1,531)$ & $0.35 \pm 0.17(1,084)$ & $1.80 \pm 0.43(1,084)$ \\
\hline \multicolumn{6}{|l|}{ Species specific } \\
\hline Abies-Picea & $0.31 \pm 0.24(49)$ & $0.27 \pm 0.34(49)$ & $1.58 \pm 0.54(49)$ & $0.36 \pm 0.33$ & $1.93 \pm 0.77(33)$ \\
\hline Cunninghamia lanceolata & $0.21 \pm 0.13(318)$ & $0.28 \pm 0.28(318)$ & $1.49 \pm 0.39(318)$ & $0.37 \pm 0.18(254)$ & $1.83 \pm 0.48(254)$ \\
\hline Cupressus-Fokienia & $0.24 \pm 0.07(43)$ & $0.27 \pm 0.22(43)$ & $1.51 \pm 0.26(43)$ & $0.34 \pm 0.10(39)$ & $1.80 \pm 0.30(39)$ \\
\hline Larix & $0.22 \pm 0.15(102)$ & $0.08 \pm 0.05(102)$ & $1.29 \pm 0.18(102)$ & $0.33 \pm 0.11(49)$ & $1.64 \pm 0.27(49)$ \\
\hline Pinus koraiensis & $0.32 \pm 0.14(35)$ & $0.23 \pm 0.13(35)$ & $1.56 \pm 0.27(35)$ & $0.36 \pm 0.10(33)$ & $1.92 \pm 0.37(33)$ \\
\hline P. massoniana & $0.23 \pm 0.17(112)$ & $0.12 \pm 0.14(112)$ & $1.35 \pm 0.30(112)$ & $0.25 \pm 0.09(78)$ & $1.65 \pm 0.40(78)$ \\
\hline P. tabulaeformis & $0.36 \pm 0.19(124)$ & $0.27 \pm 0.21(124)$ & $1.64 \pm 0.39(124)$ & $0.35 \pm 0.09(87)$ & $1.95 \pm 0.43(87)$ \\
\hline Acacia & $0.26 \pm 0.16(29)$ & $0.16 \pm 0.13(29)$ & $1.42 \pm 0.25(29)$ & $0.32 \pm 0.18(22)$ & $1.75 \pm 0.40(22)$ \\
\hline Betula-Populus & $0.30 \pm 0.13(106)$ & $0.11 \pm 0.09(106)$ & $1.42 \pm 0.18(106)$ & $0.36 \pm 0.20(44)$ & $1.73 \pm 0.29(44)$ \\
\hline Castanopsis & $0.31 \pm 0.16(32)$ & $0.09 \pm 0.06(32)$ & $1.41 \pm 0.20(32)$ & $0.37 \pm 0.12(21)$ & $1.81 \pm 0.30(21)$ \\
\hline Casuarina & $0.17 \pm 0.08(15)$ & $0.15 \pm 0.13(15)$ & $1.34 \pm 0.20(15)$ & $0.22 \pm 0.11(12)$ & $1.58 \pm 0.32(12)$ \\
\hline Eucalyptus & $0.14 \pm 0.10(88)$ & $0.08 \pm 0.06(88)$ & $1.22 \pm 0.15(88)$ & $0.26 \pm 0.08(59)$ & $1.50 \pm 0.20(59)$ \\
\hline Pheobe & $0.16 \pm 0.09(14)$ & $0.07 \pm 0.03(14)$ & $1.23 \pm 0.11(14)$ & $0.36 \pm 0.11(14)$ & $1.60 \pm 0.19(14)$ \\
\hline Quercus (deciduous) & $0.28 \pm 0.10(37)$ & $0.06 \pm 0.05(37)$ & $1.34 \pm 0.12(37)$ & $0.39 \pm 0.13(28)$ & $1.73 \pm 0.22(28)$ \\
\hline Robinia pseudoacacia & $0.33 \pm 0.15(29)$ & $0.08 \pm 0.07(29)$ & $1.42 \pm 0.17(29)$ & $0.41 \pm 0.22(20)$ & $1.78 \pm 0.35(20)$ \\
\hline Rainforest and monsoon rainforest & $0.27 \pm 0.09(30)$ & $0.08 \pm 0.12(30)$ & $1.35 \pm 0.17(30)$ & $0.30 \pm 0.03(19)$ & $1.63 \pm 0.13(19)$ \\
\hline $\begin{array}{l}\text { Cunninghamia lanceolata and } \\
\text { broadleaved mixed forest }\end{array}$ & $0.33 \pm 0.13(49)$ & $0.28 \pm 0.21(49)$ & $1.61 \pm 0.32(49)$ & $0.39 \pm 0.17(34)$ & $1.98 \pm 0.53(34)$ \\
\hline $\begin{array}{l}\text { P. massoniana and broadleaved } \\
\text { mixed forest }\end{array}$ & $0.25 \pm 0.14(21)$ & $0.08 \pm 0.06(21)$ & $1.33 \pm 0.19(21)$ & $0.27 \pm 0.08$ (19) & $1.61 \pm 0.25(19)$ \\
\hline Deciduous forests & $0.28 \pm 0.14(338)$ & $0.09 \pm 0.08(338)$ & $1.38 \pm 0.19(338)$ & $0.37 \pm 0.17(183)$ & $1.72 \pm 0.30(183)$ \\
\hline Evergreen forests & $0.26 \pm 0.17(1133)$ & $0.21 \pm 0.22(1133)$ & $1.47 \pm 0.35(1133)$ & $0.34 \pm 0.17(856)$ & $1.81 \pm 0.45(856)$ \\
\hline Pine forests & $0.31 \pm 0.19(376)$ & $0.21 \pm 0.19(376)$ & $1.53 \pm 0.35(376)$ & $0.33 \pm 0.13(271)$ & $1.87 \pm 0.45(271)$ \\
\hline
\end{tabular}




\subsection{Influences of climate on BEFs}

Across China's forests, branch BEFs, leaf BEFs, and aboveground $\mathrm{BEFs}$ increased with increasing MAT and then declined beyond ca. $7.7-8.5^{\circ} \mathrm{C}(P<0.001)$ (Fig. 2a-c), whereas root BEFs and whole tree BEFs decreased $(P<0.001)$ (Fig. $2 \mathrm{~d}$ and e). The relationships of BEFs with MAT were different between deciduous forests and evergreen forests (Fig. 2). In deciduous forests, branch BEFs and aboveground BEFs increased with MAT $(P<0.001)$ (Fig. $2 \mathrm{f}$ and h), but other BEFs showed no trends with MAT $(P>0.05)$ (Fig. 2g-j). However, all BEFs of evergreen forests decreased with MAT $(P<0.001)$ (Fig. $2 \mathrm{k}-0)$, which was also the case in pine forests $(P<0.001)($ Fig. $2 p-t)$.

With increasing MAP, branch BEFs, leaf BEFs, aboveground BEFs, and whole BEFs decreased significantly across China's forests $(P<0.001)$ (Fig. 3a-e), whereas root BEFs decreased and then increased above $1,400 \mathrm{~mm}(P<$ 0.001) (Fig. 3d). Deciduous forests and evergreen forests showed different relationships between BEFs and MAP (Fig. 3). Root BEFs of deciduous forests decreased with MAP $(P<0.001)$ (Fig. 3i), while other BEFs had no trends with MAP $(P>0.05)$ (Fig. $3 \mathrm{f}-\mathrm{j})$; root BEFs of evergreen forests decreased with MAP and then increased above $1,400 \mathrm{~mm}(P<0.001)$ (Fig. 3n), while other BEFs showed increasing trends with MAP $(P<0.001)$ (Fig. $3 \mathrm{k}-0)$. BEFs of pine forests decreased with MAP $(P<0.001)$ (Fig. $3 p-t)$.

\subsection{Influences of stand development on BEFs}

All BEFs displayed significant relationships with a range of factors associated with stand development (Table 3). They decreased significantly $(P<0.001)$ with stand age, mean $\mathrm{DBH}$, mean tree height, standing volume, and stem biomass. However, an increasing trend with stand density was found for BEFs except branch BEF $(P<0.001$ for all except $P=$ 0.97 for branch $\mathrm{BEF})$. Among these stand variables, mean tree height was generally the most powerful for explaining BEFs and could explain 29, 53, 31, and $58 \%$ of the total variances of branch BEFs, leaf BEFs, aboveground BEFs, root $\mathrm{BEFs}$, and whole BEFs, respectively.

\section{Discussion}

Two methods have generally been used in inventory-based forest biomass and carbon estimations: stand biomass equations (i.e., stand-level total or component biomass as a function of stand-level volume) (Lehtonen et al. 2004; Pan et al. 2004) and transformation factors (e.g., WD and BEFs) (IPCC 2003; Somogyi et al. 2007). WD and BEFs can be combined into biomass conversion and expansion factors (BCEFs, defined as the ratios of biomass to volume) (IPCC
2006; Lehtonen et al. 2004). In practice, transformation factors (e.g., WD and BEFs) are more commonly applied than stand biomass equations (IPCC 2006). Furthermore, accurate inventory-based estimates can be obtained using either WD and BEFs or BCEFs when these factors have been derived locally (IPCC 2006).

There are many databases and publications currently available which provide WD values for tree species of China's forests, ranging from boreal species to tropical species (Zhang et al. 2011), and which could be used to easily convert volume to biomass. However, although the variability of WD values at the national scale has also been examined (Zhang et al. 2011), the other factor, BEFs, has not been analyzed previously. Therefore, using our current comprehensive biomass dataset of China's forests, here, we reported values for various BEFs and explored variations in BEFs in relation to forest type, climate, and stand development at the national scale in China for the first time. Our results will be helpful to select suitable values for BEFs and to develop the predictive models to accurately determine BEFs, thereby reducing the uncertainty in estimates of forest biomass and carbon stocks.

\subsection{Factors influencing BEFs}

According to the means and standard deviations given in Table 1, coefficients of variation (expressed as a percentage) were in increasing order: aboveground BEFs $(22 \%)$, whole BEFs (24\%), root BEFs (48 \%), branch BEFs (60\%), and leaf BEFs (109\%). This indicates that BEFs, especially leaf $\mathrm{BEF}$, branch $\mathrm{BEF}$, and root $\mathrm{BEF}$, could be sensitive to biotic and abiotic factors and also might have different inherent variation in the biomass allocations among tree components. Therefore, knowledge of the sources of variation in BEFs is fundamental to reducing uncertainties in BEFs, thereby improving the accuracy of the estimates of forest biomass and carbon stocks.

\subsubsection{Influence of stand development on BEFs}

Our study found that BEFs decreased with stand age and size (e.g., DBH, tree height, and standing volume). Similar results have been observed in specific forest types, for example, aboveground BEF for tropical forest (Brown et al. 1989) and Picea sitchensis forest (Tobin and Nieuwenhuis 2007) and whole BEF for Chamaecyparis obtusa forest and Cryptomeria japonica forest (Fukuda et al. 2003). A general principle has been illustrated: the proportion of stem biomass in tree biomass increases as trees grow, while the proportions of other tree components decrease proportionally (or remain more or less unchanged) (Landsberg and Sands 2011). Thus, the trend for BEFs to decrease with stand development appears to be a result of 
Table 2 Comparison of BEFs between functional groups

\begin{tabular}{|c|c|c|c|c|c|}
\hline Forest trait ${ }^{\mathrm{a}}$ & Branch BEF & Leaf BEF & Aboveground BEF & Root BEF & Whole BEF \\
\hline \multicolumn{6}{|l|}{ Leaf lifespan ${ }^{\mathrm{b}}$} \\
\hline Deciduous forests & $0.23 a \pm 0.13$ & $0.06 \mathrm{~b} \pm 0.04(160)$ & $1.29 b \pm 0.14(160)$ & $0.35 \mathrm{a} \pm 0.14(93)$ & $1.63 \mathrm{a} \pm 0.23(93)$ \\
\hline Evergreen forests & $0.25 \mathrm{a} \pm 0.15(510)$ & $0.13 \mathrm{a} \pm 0.11(510)$ & $1.39 \mathrm{a} \pm 0.24(510)$ & $0.30 \mathrm{~b} \pm 0.11$ & $1.66 \mathrm{a} \pm 0.29(380)$ \\
\hline \multicolumn{6}{|l|}{ Leaf form } \\
\hline Coniferous forests & $0.23 a \pm 0.15$ & $0.14 \mathrm{a} \pm 0.11$ & $1.37 \mathrm{a} \pm 0.25$ (469) & $0.29 b \pm 0.11$ & $1.65 a \pm 0.30(321)$ \\
\hline Broadleaved forests & $0.28 b \pm 0.13$ & $0.06 \mathrm{~b} \pm 0.04(182)$ & $1.34 \mathrm{a} \pm 0.15$ & $0.35 \mathrm{a} \pm 0.13$ & $1.67 \mathrm{a} \pm 0.21(134)$ \\
\hline \multicolumn{6}{|l|}{ Stand origin } \\
\hline Natural forests & $0.26 \mathrm{a} \pm 0.13(267)$ & $0.08 b \pm 0.06(267)$ & $1.34 \mathrm{a} \pm 0.17(267)$ & $0.34 \mathrm{a} \pm 0.13$ & $1.69 a \pm 0.26(170)$ \\
\hline Plantations & $0.24 \mathrm{a} \pm 0.15$ & $0.13 \mathrm{a} \pm 0.11$ & $1.38 \mathrm{a} \pm 0.25(422)$ & $0.29 b \pm 0.10$ & $1.64 \mathrm{~b} \pm 0.28(319)$ \\
\hline \multicolumn{6}{|l|}{ Species genera } \\
\hline Cunninghamia & $0.12 \mathrm{c} \pm 0.05$ & $0.09 \mathrm{~b} \pm 0.05(89)$ & $1.22 \mathrm{c} \pm 0.10(89)$ & $0.24 c \pm 0.06$ & $1.45 b \pm 0.11(75)$ \\
\hline Larix & $0.15 b \pm 0.06(71)$ & $0.05 c \pm 0.03$ & $1.20 \mathrm{c} \pm 0.08$ & $0.28 b c \pm 0.07(30)$ & $1.45 \mathrm{~b} \pm 0.11(30)$ \\
\hline Picea & $0.26 a \pm 0.13(38)$ & $0.19 a \pm 0.13$ & $1.46 a \pm 0.19(38)$ & $0.31 \mathrm{ab} \pm 0.12(23)$ & $1.78 \mathrm{a} \pm 0.26(23)$ \\
\hline Pinus & $0.28 \mathrm{a} \pm 0.15$ & $0.17 \mathrm{a} \pm 0.12$ & $1.45 \mathrm{a} \pm 0.27(229)$ & $0.31 b \pm 0.11(155)$ & $1.73 a \pm 0.31(155)$ \\
\hline Quercus (deciduous) & $0.28 \mathrm{a} \pm 0.11$ & $0.05 c \pm 0.03$ & $1.33 b \pm 0.12$ & $0.39 \mathrm{a} \pm 0.13$ & $1.73 \mathrm{a} \pm 0.22(28)$ \\
\hline
\end{tabular}

${ }^{a}$ Only older stands $(\geq 20$ years) were used in this table. Mean \pm SD and the number of samples are in parentheses. Different small letters indicate significant differences between functional groups $(P<0.05)$

${ }^{\mathrm{b}}$ Data for stands dominated jointly by deciduous and evergreen tree species were not included in this category

changes in biomass allocation as stands grow as well as the definition of the BEF factor itself.

\subsubsection{Influence of forest traits on BEFS}

BEFs showed large variation across forest types (Table 1), but not all of them varied significantly with functional groups (i.e., leaf forms, leaf lifespans, stand origins, and species genera) (Table 2). Some factors have long been considered to crucially control biomass allocation strategies for adapting to environmental conditions (Antúnez et al. 2001; Cornelissen et al. 1998; Poorter et al. 2012): photosynthetic rate and relative growth rate, leaf traits (leaf form and leaf lifespan), forest succession stage, and soil characteristics (e.g., soil water and nutrient availability). Generally, plants with higher photosynthetic rates and relative growth rates have smaller leaf proportions and larger root proportions to total biomass in order to acquire more water and nutrients for survival and maximum growth (Antúnez et al. 2001; Cornelissen et al. 1998; Reich 1998). Broadleaved trees usually have higher photosynthetic rates and relative growth rates than coniferous trees (Reich 1998), and deciduous trees have higher photosynthetic rates and relative growth rates than evergreen trees (Cornelissen et al. 1998; Reich 1998). Early-successional species such as Populus and Betula spp. generally have higher photosynthetic rates and relative growth rates than late-successional species such as Picea and Pinus spp. These could explain why coniferous forests and evergreen forests have larger leaf BEFs and lower root BEFs than broadleaved forests and deciduous forests, and also why Picea and Pinus forests had relatively higher BEFs. Plantations are generally established in more productive environments (e.g., more fertile and moister soil) than natural forests and can achieve maximum growth with lower root proportions (Luo et al. 2012). This could explain why plantations have larger root BEFs than natural forests.

\subsubsection{Influence of climate on BEFs}

In our study, whole BEF (the reciprocal of the ratio of stem to whole tree biomass) decreased significantly as MAT and MAP increased (Figs. 2e-t and 3e-t), except for deciduous forests (Figs. $2 \mathrm{j}$ and $3 \mathrm{j}$ ). This means that the proportions of stem in whole tree biomass increased as MAT and MAP increased. High temperature and precipitation would favor high tree growth and more photosynthate allocation to tree stem. That would improve the defensive capacity of trees against environmental perturbation and may help to ensure hydraulic conductivity from soil to leaves (Mencuccini et al. 2005; Ryan et al. 2006).

The responses of leaf, branch, aboveground, and root BEFs to MAT and MAP varied with tree components and forest types (e.g., deciduous forest vs. evergreen forests) (Figs. 2 and 3). The branch, leaf, and aboveground BEFs for evergreen and pine forests decreased with MAT and MAP (Figs. 2k-r and 3k-r). There are two plausible explanations for this observation. One is that the increased stem proportion with MAT and MAP would reduce branch, leaf, and aboveground BEFs of which stem biomass is the 

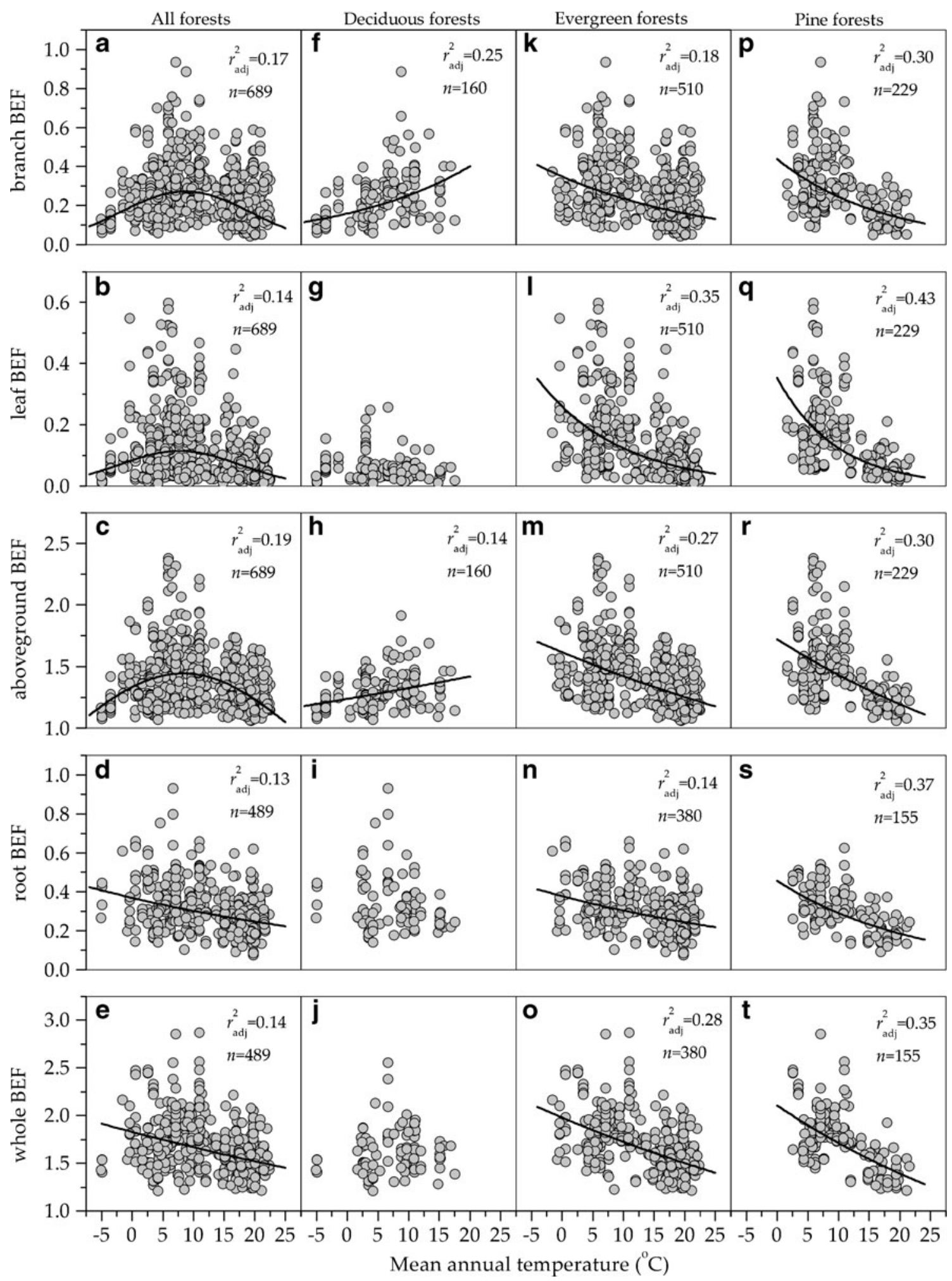

Fig. 2 The relationships between BEFs and mean annual temperature for all data pooled (a-e), deciduous forests $(\mathbf{f}-\mathbf{j})$, evergreen forests $(\mathbf{k}-\mathbf{0})$, and pine forests $(\mathbf{p}-\mathbf{t})$. All regression lines in

denominator. Another is that the increasing MAT and MAP would enhance light use efficiency, reducing the need for figures are significant at $P<0.001$, and their adjusted coefficients of determination $\left(r_{\mathrm{adj}}{ }^{2}\right)$ and the numbers of samples $(n)$ are also given

photosynthetic components including leaves and branches. For all forests investigated, the branch, leaf, and aboveground 

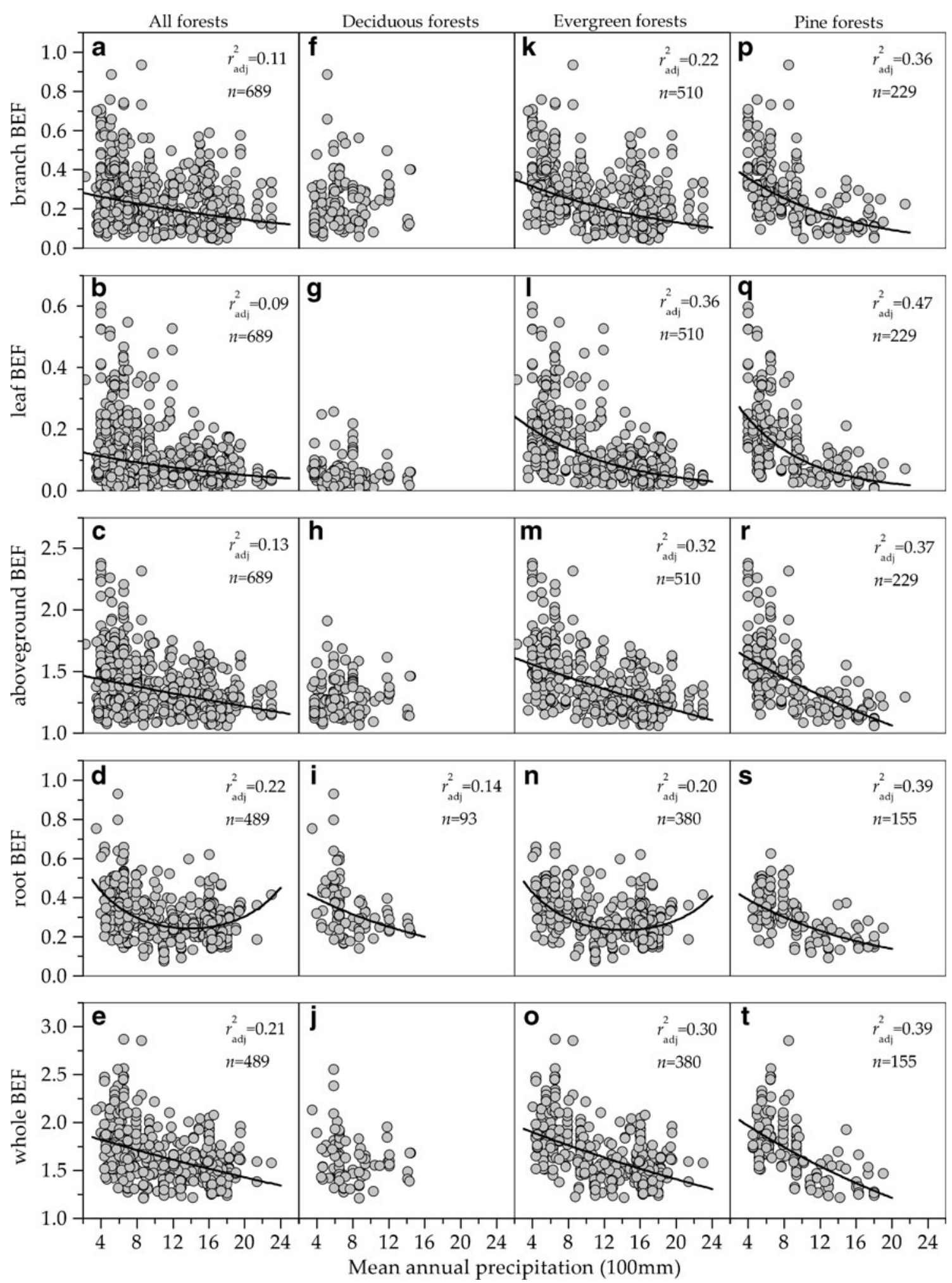

Fig. 3 The relationships between BEFs and mean annual precipitation for all data pooled $(\mathbf{a}-\mathbf{e})$, deciduous forests $(\mathbf{f}-\mathbf{j})$, evergreen forests $(\mathbf{k}-$ $\mathbf{o})$, and pine forests $(\mathbf{p}-\mathbf{t})$. All regression lines in figures are significant at $P<0.001$, and their adjusted coefficients of determination $\left(r_{\text {adj }}{ }^{2}\right)$ and the numbers of samples $(n)$ are also given

forests investigated, at low temperatures, branch BEFs, leaf BEFs, and aboveground BEFs were positively also be explained in the same way. However, for all 


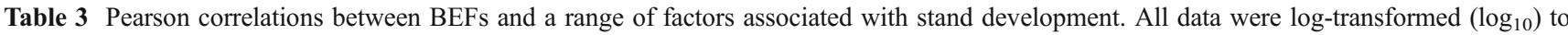
linearize the relationships between variables and also to reduce the influence of outlying data

\begin{tabular}{|c|c|c|c|c|c|c|}
\hline BEFs & $\begin{array}{l}\text { Stand age } \\
\text { (year) }\end{array}$ & $\begin{array}{l}\text { Mean DBH } \\
(\mathrm{cm})\end{array}$ & $\begin{array}{l}\text { Mean tree height } \\
\text { (m) }\end{array}$ & $\begin{array}{l}\text { Stand density (trees/ } \\
\text { ha) }\end{array}$ & $\begin{array}{l}\text { Standing volume } \\
\left(\mathrm{m}^{3} / \mathrm{ha}\right)\end{array}$ & $\begin{array}{l}\text { Stem biomass }(\mathrm{Mg} \text { ) } \\
\text { ha) }\end{array}$ \\
\hline Branch BEF & $-0.10^{*}$ & $-0.31^{*}$ & $-0.54 *$ & $0.00 \mathrm{~ns}$ & $-0.50^{*}$ & $-0.50^{*}$ \\
\hline Leaf BEF & $-0.37^{*}$ & $-0.57^{*}$ & $-0.73^{*}$ & $0.35^{*}$ & $-0.59^{*}$ & $-0.67^{*}$ \\
\hline $\begin{array}{l}\text { Aboveground } \\
\text { BEF }\end{array}$ & $-0.28^{*}$ & $-0.51^{*}$ & $-0.73^{*}$ & $0.18^{*}$ & $-0.66^{*}$ & $-0.69^{*}$ \\
\hline Root BEF & $-0.22 *$ & $-0.43^{*}$ & $-0.57^{*}$ & $0.18^{*}$ & $-0.53^{*}$ & $-0.58^{*}$ \\
\hline Whole BEF & $-0.30 *$ & $-0.59^{*}$ & $-0.76^{*}$ & $0.30 *$ & $-0.69^{*}$ & $-0.74 *$ \\
\hline
\end{tabular}

$n s$ not statistically significant $(P>0.05)$

$* P<0.001$

related to MAT (Fig. 2a-c), most likely because increasing temperature favors tree growth by providing better growth conditions (e.g., higher microbial activity and nutrient availability), resulting in more branches and leaves to transport water and photosynthesize; at higher temperatures, these BEFs were negatively correlated with MAT, which may be caused by higher transpiration and respiration requiring a reduction in biomass allocation to branches and leaves to minimize maintenance costs. Root BEF decreasing with MAT in evergreen forests and pine forests might be attributed to the fact that stem proportion increases with MAT. The responses of root BEFs to MAP showed a decreasing trend at first, then an increasing trend when MAT increased above a critical point. As MAP increases, water supply becomes abundant and trees will allocate less biomass to roots to absorb soil water and nutrients. However, when precipitation exceeds forest demand, forest production will be limited by nutrient availability rather than water, so more biomass would be allocated into roots to absorb more nutrients from the soil (Luo et al. 2012).

Apart from stand development, forest traits, and climate, management practices (e.g., thinning, pruning, and fertilizing) and soil characteristics (e.g., soil texture, nutrients, and water) may have significant effects on BEFs because they could influence biomass accumulation and partitioning of trees. However, effects of management practices and soil characteristics were not analyzed in our study, mainly due to the lack of soil data and management descriptions in original sources.

\subsection{Implications for biomass carbon estimation}

As recommended by IPCC (2003), regional forest biomass carbon storage was estimated by multiplying volume from forest inventory data (FID) by a series of transformation factors (i.e., WD, BEFs, and CF). FID provides accurate and unbiased statistics (e.g., age, area, and volume) of a region or country with high precision (Lehtonen et al. 2004; Somogyi et al. 2007). Thus, most of the uncertainty in forest biomass carbon estimates has been considered to be attributed to transformation factors, especially WD and BEFs (IPCC 2003). A growing body of studies has analyzed the sources of the variation in WD (e.g., Zhang et al. 2011) and CF (e.g., Zheng et al. 2007). For BEFs, previous studies focused on their age- and size-induced variation for specific forest types (e.g., Brown et al. 1989; Fukuda et al. 2003; Lim et al. 2012; Tobin and Nieuwenhuis 2007). Our study provided forest type-specific values of various BEFs and further examined not only age- and size-induced variation of BEFs, but also the variation of BEFs in relation to forest traits and climate.

In this study, forest type-specific values of various BEFs were provided in Table 1. When comparing our values for BEFs with others available (e.g., IPCC 2003; Tobin and Nieuwenhuis 2007), means of aboveground BEFs for China's forests and for most forest types (Table 1) were higher than the IPCC default value (1.30) (IPCC 2003), indicating that a large underestimation would result if the IPCC default value was used to estimate China's forest carbon storage.

Because of the large standard deviations in BEFs (Table 1), using constant values for BEFs, especially leaf $\mathrm{BEF}$ and branch $\mathrm{BEF}$, will produce great uncertainties in biomass and carbon estimates. Our results showed that the high standard deviations in BEFs are related to forest types (dominant species) (Table 1), functional groups (leaf forms, leaf lifespans, stand origins, and species genera) (Table 2), and MAT and MAP (Figs. 2 and 3). In order to reduce the uncertainties induced by BEFs, (1) different values of BEFs should be selected for forest types and functional groups, and (2) climatic influences (e.g., MAT and MAP) should be considered when selecting appropriate BEFs, especially for evergreen forests.

This study provided a relatively complete inventory of BEFs in China. However, to improve the accuracy of estimates of forest carbon storage in China, more work still needs to be done. (1) More locations should be covered. Available investigations showed a sound spatial distribution 
(Fig. 1) but do not cover all regions of China's forests, especially the northwest forest region. (2) Consistent methods to measure stand biomass should be developed. There were some differences in the measurement methods available, for example, different minimum diameters included, and different methods in measuring branch and leaf biomass (e.g., full-measurement method and average branch method). (3) Methods to estimate stand biomass should be comparable. Stand-level biomass was generally estimated using three methods: average tree method, stratified average tree method, and allometric equation method. Knowledge gaps should be filled. Effects of management practices and soil characteristics on BEFs have not been fully explored.

\section{Conclusion}

BEFs are important parameters for quantifying forest biomass and carbon stock. Knowledge of the sources of variation in BEFs is fundamental to reducing the uncertainty in BEFs, thereby improving the accuracy of the estimates of forest biomass and carbon stocks. However, prior to this study, there has been little information on possible causes of the variability in BEFs at large scales.

Our study was the first to provide specific values of BEFs across the range of China's forest types and to examine the variation of BEFs according to forest types, climate, and stand development (stand age and size). BEFs had a large variation in relation to forest types (dominant species) and functional groups (leaf forms, leaf lifespans, stand origins, and species genera), stand age and size, and climate (MAT and MAP). These results indicate that (1) different values of BEFs should be applied when developing estimates of forest biomass and carbon stocks for different forest types, leaf forms, leaf lifespans, stand origins, and species genera, and (2) stand development (especially tree height) and climate should be considered in the accurate determination of BEFs. However, effects of management practices and soil characteristics were not examined. Therefore, future studies should place particular emphasis on the effects of management practices and soil characteristics and also on the development of BEF functions with influencing factors (e.g., tree height, climate, and soil characteristics) as predictor variables for a specified forest type, thereby reducing uncertainties induced by BEFs in estimates of forest biomass and carbon stock at large scales.

Acknowledgments This study was supported by the Strategic Priority Program of the Chinese Academy of Sciences (CAS) (XDA05060102 and XDA05050602), National Natural Science Foundation of China (31200363 and 31270588), National Forestry Public Welfare Program of China (201304205 and 201204604), CAS/SAFEA International Partnership Program for Creative Research Teams (KZCX2-YW-T08),
CAS Knowledge Innovation Program (KZCX-2-YW-453), CAS Youth Innovation Program (Y2L0331D60), and Fujian Provincial Science and Technology Program (2011Y0052). We thank Dr. Xiaohua Wei (The University of British Columbia), the anonymous reviewers, and the handling editor for their valuable comments on the manuscript, and also thank Dr. Jonathan Vause (Chinese Academy of Sciences) for his helpful language polishing.

\section{References}

Antúnez I, Retamosa EC, Villar R (2001) Relative growth rate in phylogenetically related deciduous and evergreen woody species. Oecologia 128:172-180

Brown S, Gillespie AJR, Lugo AE (1989) Biomass estimation methods for tropical forests with applications to forest inventory data. For Sci 35:881-902

Cornelissen JHC, Castro-Díez P, Carnelli AL (1998) Variation in relative growth rate among woody species. In: Lambers $\mathrm{H}$, Poorter H, van Vuuren MMI (eds) Inherent variation in plant growth: physiological mechanisms and ecological consequences. Backhuys Publishers, Leiden, pp 363-392

Fang J, Brown S, Tang Y, Nabuurs GJ, Wang X, Shen H (2006) Overestimated biomass carbon pools of the northern mid and high latitude forests. Clim Chang 74:355-368

Feng Z, Wang X, Wu G (1999) Biomass and productivity of forest ecosystems in China. Science Press, Beijing, 241pp (In Chinese)

Fukuda M, Iehara T, Matsumoto M (2003) Carbon stock estimates for sugi and hinoki forests in Japan. For Ecol Manag 184:1-16

Hijmans RJ, Cameron SE, Parra JL, Jones PG, Jarvis A (2005) Very high resolution interpolated climate surfaces for global land areas. Int J Climatol 25:1965-1978

Houghton RA, Hall F, Goetz SJ (2009) Importance of biomass in the global carbon cycle. J Geophys Res 114:G00E03

Intergovernmental Panel on Climate Change (IPCC) (2003) Good practice guidance for land use, land-use change and forestry. Institute for Global Environmental Strategies, Kanagawa

IPCC (2006) 2006 IPCC guidelines for national greenhouse gas inventories (vol. 4): agriculture, forestry and other land use. Institute for Global Environmental Strategies, Kanagawa

Johnson WC, Sharpe DM (1983) The ratio of total to merchantable forest biomass and its application to the global carbon budget. Can J For Res 13:372-383

Kauppi PE, Tomppo E, Ferm A (1995) C and N storage in living trees within Finland since the 1950s. Plant Soil 168-169:633-638

Kloeke AEEO, Douma JC, Ordoñez JC, Reich PB, Bodegom PM (2012) Global quantification of contrasting leaf life span strategies for deciduous and evergreen species in response to environmental conditions. Glob Ecol Biogeogr 21:224-235

Landsberg J, Sands P (2011) Physiological ecology of forest production: principles, processes and models. Academic, London, $331 \mathrm{pp}$

Lehtonen A, Mäkipää R, Heikkinen J, Sievänen R, Liski J (2004) Biomass expansion factors (BEFs) for Scots pine, Norway spruce and birch according to stand age for boreal forests. For Ecol Manag 188:211-224

Levy PE, Hale SE, Nicoll BC (2004) Biomass expansion factors and root:shoot ratios for coniferous tree species in Great Britain. Forestry 77:421-430

Lim H, Lee K-H, Lee KH, Park IH (2012) Biomass expansion factors and allometric equations in an age sequence for Japanese cedar (Cryptomeria japonica) in southern Korea. J For Res. doi:10.1007/s10310-012-0353-2 
Luo T (1996) Patterns of net primary productivity for Chinese major forest types and their mathematical models. Ph.D. dissertation, Commission for Integrated Survey of Natural Resources, Chinese Academy of Sciences, Beijing, 211pp (In Chinese with English abstract)

Luo Y, Wang X, Zhang X, Booth TH, Lu F (2012) Root:shoot ratios across China's forests: forest type and climatic effects. For Ecol Manag 269:19-25

Mencuccini M, Martinez-Vilalta J, Vanderklein D, Hamid HA, Korakaki E, Lee S, Michiels B (2005) Size-mediated ageing reduces vigour in trees. Ecol Lett 8:1183-1190

Nogueira EM, Fearnside PM, Nelson BW, Barbosa RI, Keizer EWH (2008) Estimates of forest biomass in the Brazilian Amazon: new allometric equations and adjustments to biomass from woodvolume inventories. For Ecol Manag 256:1853-1867

Pan Y, Luo T, Birdsey R, Hom J, Melillo J (2004) New estimates of carbon storage and sequestration in China's forests: effects of ageclass and method on inventory-based carbon estimation. Clim Chang 67:211-236

Poorter H, Niklas KJ, Reich PB, Oleksyn J, Poot P, Mommer L (2012) Biomass allocation to leaves, stems, and roots: meta-analysis of interspecific variation and environmental control. New Phytol 193:30-50

Reich PB (1998) Variation among plant species in leaf turnover rates and associated traits: implications for growth at all life stages. In: Lambers H, Poorter H, van Vuuren MMI (eds) Inherent variation in plant growth: physiological mechanisms and ecological consequences. Backhuys Publishers, Leiden, pp 467-487

Ren Y, Yan J, Wei X, Wang Y, Yang Y, Hua L, Xiong Y, Niu X, Song X (2012) Effects of rapid urban sprawl on urban forest carbon stocks: integrating remotely sensed, GIS and forest inventory data. J Environ Manag 113:447-455

Ryan MG, Phillips N, Bond BJ (2006) The hydraulic limitation hypothesis revisited. Plant Cell Environ 29:367-381

Shao G, Dai L, Dukes JS, Jackson RB, Tang L, Zhao J (2011) Increasing forest carbon sequestration through cooperation and shared strategies between China and the United States. Environ Sci Technol 45:2033-2034

Somogyi Z, Cienciala E, Mäkipää R, Muukkonen P, Lehtonen A, Weiss P (2007) Indirect methods of large-scale forest biomass estimation. Eur J For Res 126:197-207

Tobin B, Nieuwenhuis M (2007) Biomass expansion factors for Sitka spruce (Picea sitchensis (Bong.) Carr.) in Ireland. Eur J For Res 126:189-196

Usoltsev VA, Hoffmann CW (1997) Combining harvest sample data with inventory data to estimate forest biomass. Scand J For Res $12: 273-279$

Wang X, Fang J, Zhu B (2008) Forest biomass and root-shoot allocation in northeast China. For Ecol Manag 255:40074020

Zhang S, Slik JWF, Zhang J, Cao K (2011) Spatial patterns of wood traits in China are controlled by phylogeny and the environment. Glob Ecol Biogeogr 20:241-250

Zhang X (2007) Vegetation map of China and its geographic patterns. Geological Publishing House, Beijing, pp 91-124 (In Chinese)

Zheng W, Bao W, Gu B, He X, Leng L (2007) Carbon concentration and its characteristics in terrestrial higher plants. Chin J Ecol 26:307-313 (In Chinese with English abstract) 